\title{
Desconstruindo o racismo social a partir da investigação de nossa ancestralidade biológica
}

Deconstructing social racism from the investigation of our biological ancestry

Erineti Arnholz ${ }^{1}$, Diógina Barata², Dalana Campos Muscardi ${ }^{3}$

${ }^{1}$ Programa de Pós-Graduação em Rede em Ensino de Biologia (PROFBIO), Universidade Federal do Espírito Santo, São Mateus, Espírito Santo, Brasil.

${ }^{2}$ Universidade Federal do Espírito Santo, Departamento de Ciências Agrárias e Biológicas, São Mateus, Espírito Santo, Brasil.

${ }^{3}$ Universidade Federal do Espírito Santo, Departamento de Educação e Ciências Humanas, São Mateus, Espírito Santo, Brasil.

Autor para correspondência: Erineti Arnholz

EEEFM Fazenda Emílio Schroeder

Estrada Alto Santa Maria, S/N, Alto Rio Possmoser - Zona Rural, CEP 29.645-000,

Santa Maria de Jetibá, Espírito Santo, Brasil

Tel: +55 27 99632-4772

Email: netiarnholz@hotmail.com

Submetido em 21/12/2020

Aceito em 21/12/2020 


\section{RESUMO}

O trabalho trata-se de uma proposta de atividade investigativa sobre o tema Evolução humana e diversidade étnicocultural para as aulas de Biologia do ensino médio, tendo como objetivo pesquisar e entender a evolução humana, compreendendo a diversidade humana como o resultado da variação genotípica e fenotípica. A partir destes, construir os conceitos de raça, etnia, preconceito e racismo, levando a reflexão a respeito do racismo e da valorização da diversidade étnico-cultural. A atividade requer conhecimentos prévios do conteúdo, pode ser interdisciplinar e não requer materiais de difícil acesso.

Palavras-chave: Biologia. Evolução Humana. Diversidade Étnico-cultural. Atividade Investigativa. Ensino.

\section{ABSTRACT}

The work is a proposal for an investigative activity on the theme Human Evolution and ethnic-cultural diversity for high school Biology classes with the aim of researching and understanding human evolution, understanding human diversity as a result of genotypic and phenotypic variation. From these, they build the concepts of race, ethnicity, prejudice and racism, leading to reflection on racism and the appreciation of ethnic-cultural diversity. The activity requires prior knowledge of the content, can be interdisciplinary and does not require difficult to access materials.

Keywords: Biology. Human evolution. Ethnic-cultural diversity. Investigative Activity. Teaching. 


\section{INTRODUÇÃO}

A sociedade brasileira é formada a partir da miscigenação de diferentes povos e as suas manifestações culturais (ameríndios, afrodescendentes, orientais e europeus). No entanto, a discriminação, o preconceito étnico racial, o descaso e a falta de oportunidades ainda são problemas vivenciados cotidianamente pela população negra no Brasil (SCHWARCZ, 2019). Nesse sentido, “a (re)educação das relações étnico-raciais no âmbito escolar é muito importante para a redução do preconceito e da discriminação racial, podendo ser desenvolvida em todas as disciplinas" (CASTRO, 2018, p. 8).

Os principais objetivos do ensino de biologia, pautados na alfabetização científica, referem-se à aprendizagem de conceitos básicos das ciências biológicas, à análise do processo de investigação científica e ao reconhecimento das implicações da ciência e tecnologia nas relações sociais (KRASILCHIK, 2008).

Mediante o exposto, a disciplina de biologia oferece múltiplas possibilidades de conteúdos que podem contribuir com (re)educação das relações étnico raciais, como por exemplo a variabilidade genética e a ausência de diferenciação em raça na espécie humana, fundamentado através de estudos comparativos de genética molecular e populacional (PENNA, 2006). É um assunto que tem o potencial de promover um diálogo problematizador e contextualizado contra o racismo, através de estudos que demonstram que a maior variabilidade genética de nossa espécie está dentro dos grupos considerados da mesma "raça", sendo as diferenças individuais muito mais representativas do que entre grupos sociais (GRAVINA, 2019).

A história da evolução humana que indica a África como berço da espécie humana e do desenvolvimento civilizatório, também representa uma alternativa para contextualização do racismo. Ainda que existam controvérsias sobre a origem e evolução da espécie humana (Homo sapiens), a teoria mais aceita e difundida entre a comunidade científica é a chamada "Fora da África Recente", onde a espécie humana atual surge na África em torno de 200 mil anos atrás e substitui as populações dos descendentes de Homo erectus que já habitavam também a Europa e a Ásia, tal como o Neandertal (SANTOS, 2014). Essa teoria evidencia a origem e ancestralidade da espécie humana no continente Africano, o que representa um conhecimento que pode contribuir para desconstrução dos preconceitos étnicos raciais que são reproduzidos na sociedade.

Health and Biosciences, v.1, n.3, Dez. 2020

Disponível em: https://periodicos.ufes.br/healthandbiosciences 
Em face ao exposto, apresentamos uma sequência didática que pode ser desenvolvida de forma transversal, ou interdisciplinarmente, e expõe os estudantes a situações problema existentes no cotidiano, instiga-os e os desafia a buscar conhecimentos no campo de estudo da biologia para a desconstrução do racismo estruturado.

\section{OBJETIVOS}

$\checkmark$ Pesquisar e entender a evolução humana.

$\checkmark$ Compreender a diversidade humana como resultado da variação genotípica e fenotípica dentro da mesma espécie.

$\checkmark$ Construir os conceitos de raça, etnia, preconceito e racismo.

$\checkmark$ Refletir a respeito do racismo e da valorização da diversidade étnico-cultural.

\section{METODOLOGIA}

\section{Materiais utilizados}

- Projetor de imagens;

- Dispositivos eletrônicos com acesso à internet;

- Laboratório de informática;

- Cartazes;

- Painel;

- Copiadora para impressão de questionários;

- Livro didático.

\section{Desenvolvimento}

$1^{a}$ etapa- Problematização inicial e elaboração de hipóteses- socializar com os estudantes, através de vídeos ou reportagens impressas, situações corriqueiras transmitidas pelos veículos de comunicação que representem o racismo. Uma sugestão é o episódio "Gabriel foi alvo de fake News ao fotografar região próxima ao trabalho" reportagem exibida no programa de televisão "Encontro com Fátima Bernardes", no dia 14 de outubro de 2019, em um canal de televisão aberta. O vídeo aborda a história de um rapaz que sofreu racismo no bairro onde trabalhava, pois ao fotografar a paisagem foi considerado um ladrão devido a sua cor. Esta informação foi propagada pela população do bairro através de uma série de fake News a seu respeito, divulgadas em grupos de envio de mensagens por aplicativo.

Health and Biosciences, v.1, n.3, Dez. 2020 
Após a exibição ou debate das reportagens ou textos, provocar e construir junto com os estudantes indagações que os façam refletir sobre a origem do preconceito racial que vivenciamos no cotidiano, as diferenças que existem entre indivíduos, o uso da denominação de raças entre os povos, a origem e a evolução da espécie humana. É de fundamental importância que a elaboração dos questionamentos fique a cargo dos estudantes, no entanto, em caso de dúvidas em relação a elaboração, as questões a seguir podem ser utilizadas.

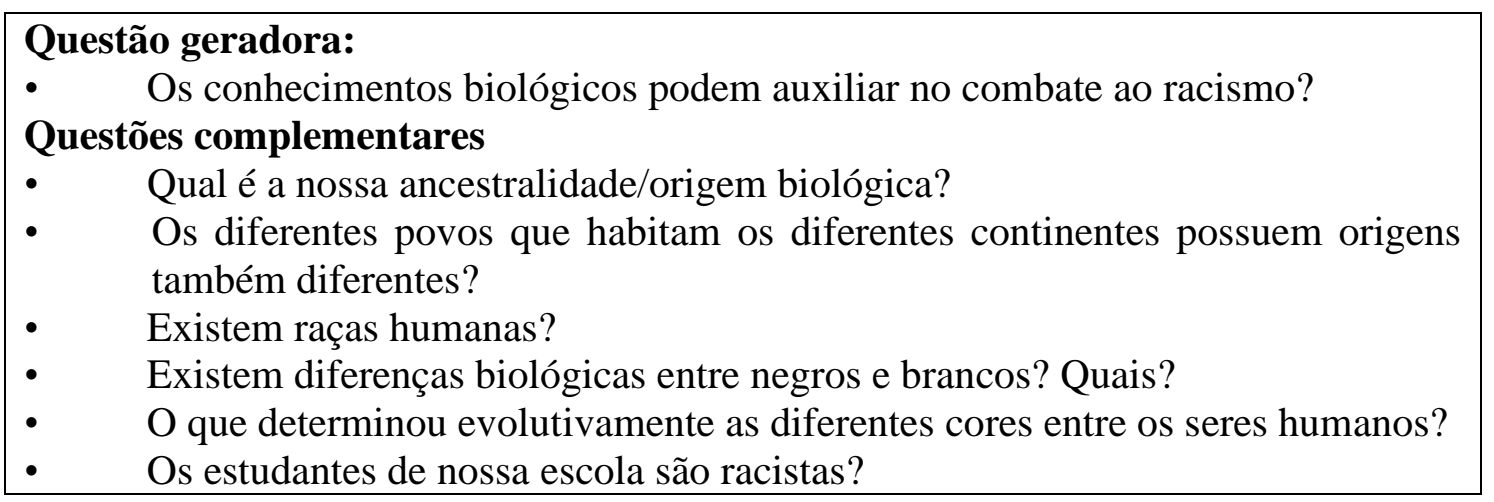

Na sequência, motivar os estudantes a elaborar hipóteses para suas indagações, que posteriormente serão confirmadas ou refutadas através de pesquisas bibliográficas e aplicação de questionário de opinião que será elaborado por eles com perguntas abertas e fechadas sobre conceitos e comportamentos racistas vivenciados e observados no cotidiano da comunidade. $2^{a}$ etapa- produção de dados - aplicação do questionário elaborado na etapa anterior para os alunos das outras turmas da escola e/ou comunidade e tabulação das informações obtidas.

$3^{a}$ etapa- Pesquisa bibliográfica - utilizando o máximo de recursos possíveis, sites, textos virtuais, artigos científicos, vídeos, documentários, livro didático, páginas interativas, os estudantes deverão pesquisar sobre as indagações por eles elaboradas coletando informações para confirmar ou refutar suas hipóteses. O ideal é que o educador já indique de antemão sites confiáveis por onde os estudantes possam navegar e realizar as suas pesquisas. No quadro, a seguir, deixamos algumas sugestões.

Health and Biosciences, v.1, n.3, Dez. 2020 


\begin{tabular}{|l|l|}
\hline \multicolumn{1}{|c|}{ Tipo de material } & \multicolumn{1}{|c|}{ Título/Referência } \\
\hline Vídeo & $\begin{array}{l}\text { Seus antepassados através do DNA. Disponível em } \\
\text { https://www.youtube.com/watch?v=IpldLd_XCm4. }\end{array}$ \\
\hline Acesso dia 28 de maio de 2020. \\
\hline $\begin{array}{l}\text { Texto de divulgação } \\
\text { científica }\end{array}$ & $\begin{array}{l}\text { Pena, SD. 2006. Uma pequena história da individualidade genética } \\
\text { humana. Ciência Hoje. (publicado on-line) 13.10.2006. }\end{array}$ \\
\hline $\begin{array}{l}\text { Texto de divulgação } \\
\text { científica }\end{array}$ & $\begin{array}{l}\text { Pena, SD. 2010. A revolução dos testes de DNA. Ciência Hoje. } \\
\text { (publicado on-line) 09.07.2010. }\end{array}$ \\
\hline Página na web & $\begin{array}{l}\text { Página interativa Entendendo a Evolução. Disponível em } \\
\text { https://evosite.ib.usp.br/evo101/index.shtml. Acesso em 28 de maio } \\
\text { de 2020. em }\end{array}$ \\
\hline Página na web & $\begin{array}{l}\text { Museu virtual da evolução. } \\
\text { https://sites.google.com/site/pensaraevolucao/museu-virtual-da- } \\
\text { evolucao. Acesso em 29 de maio de 2020. }\end{array}$ \\
\hline Página na web & $\begin{array}{l}\text { Página interativa sobre evolução humana do laboratório de } \\
\text { biodiversidade e evolução molecular da Universidade Federal de } \\
\text { Minas Gerais. Disponível em: } \\
\text { interahttp://labs.icb.ufmg.br/lbem/aulas/grad/evol/humevol/index.ht } \\
\text { ml. Acesso em 15 de outubro de 2019. }\end{array}$ \\
\hline
\end{tabular}

\section{$4^{a}$ etapa-Discussão dos dados pesquisados}

De posse das informações levantadas durante a pesquisa e dos dados produzidos através dos questionários aplicados na escola e/ou comunidade, os alunos deverão retomar suas hipóteses iniciais e através da discussão grupal confirmar ou refutá-las.

\section{$5^{a}$ etapa- Ampliação e comunicação}

Em grupos de trabalho, os estudantes podem ser motivados a produzir um material de aplicação e comunicação sobre o conhecimento obtido. A escola pode organizar uma apresentação coletiva e abrir para a comunidade, onde os dados obtidos serão exibidos pelos estudantes através de palestras ou apresentações artísticas. Caso essa sugestão não seja aplicável, a elaboração de mapas conceituais, panfletos, textos argumentativos e histórias em quadrinhos podem ser alternativas para que os estudantes expressem os conceitos abordados e os conhecimentos construídos. Também pode ser interessante a produção de vídeos, podcasts, páginas na web e blogs. O material produzido poderá abordar os dados pesquisados para confirmação ou refutação das hipóteses iniciais, bem como apresentar as informações obtidas nos questionários aplicados a todos os estudantes da escola e/ou demais envolvidos. 


\section{PONTOS INVESTIGATIVOS DA ATIVIDADE}

Para que uma atividade curricular proposta tenha um caráter investigativo é necessário que os estudantes sejam motivados à problematização ou mesmo problematizem uma determinada situação ou um conjunto de dados, elaborem questionamentos, pensem em hipóteses que respondam os questionamentos realizados e busquem explicações para as problematizações apresentadas de forma experimental ou documental. Scarpa \& Silva (2013) colocam que o ensino de biologia por investigação pode ocorrer tanto por meio de experimentações em laboratórios quanto por meio de observação do mundo natural, comparação entre fenômenos, busca e análise de diferentes fontes de pesquisa (livros, internet, filmes), de jogos, simulações e construção de narrativas históricas.

Através de uma ampla revisão da literatura sobre as características da metodologia de ensino por investigação, Pedaste et al. (2015), propõem as suas fases gerais de execução, que são a orientação, correspondente a contextualização inicial, problematização e conceitualização, envolvendo o questionamento e a emissão de hipóteses; $a$ investigação, que se refere à exploração, experimentação e interpretação dos dados e a conclusão, que é uma fase referente à comunicação dos resultados, que promove uma reflexão sobre o processo e os conhecimentos construídos.

$\mathrm{Na}$ atividade proposta, os estudantes são provocados a refletir sobre a diversidade étnica da sociedade brasileira e o preconceito racial vivenciado cotidianamente pelas pessoas de pele negra, bem como a buscar na biologia conceitos que demonstrem que a espécie humana é única, sem a existência de raças, e que as diferenças entre uns e outros se devem a fatores fenotípicos. Eles são incentivados a refletirem sobre essas questões, elaboram hipóteses, buscam no conhecimento científico respostas para suas indagações, obtém dados necessários para concluírem ou refutarem suas hipóteses iniciais apresentadas, são motivados a discutir e refletir sobre os conhecimentos obtidos e a elaborarem suas conclusões.

Além disso, esta atividade apresenta momentos de socialização e comunicação do conhecimento desenvolvido estimulado pela investigação e debate em grupos, bem como pela promoção de um momento de divulgação das conclusões obtidas que poderá envolver a escola e/ou a comunidade, o que configura um importante eixo estruturante da alfabetização científica - a compreensão da natureza das ciências e dos fatores éticos e políticos que circundam sua prática. A partir desse eixo, a ciência passa a ser compreendida como um conjunto de informações em constantes transformações, através da produção e análise de dados. É um eixo

Health and Biosciences, v.1, n.3, Dez. 2020

Disponível em: https://periodicos.ufes.br/healthandbiosciences 
que deve levar estudantes e educadores a refletirem a partir das informações obtidas (SASSERON \& CARVALHO, 2011, p. 75).

\section{CONSIDERAÇÕES}

O ensino contextualizado com questões que são vivenciadas pelos cidadãos no cotidiano que os cerca é fundamental em qualquer área do conhecimento, sobretudo na disciplina de biologia. A discriminação racial e as injustiças sociais que as pessoas negras sofrem ao longo da história da humanidade nos fazem refletir que, enquanto educadores, precisamos usar os conhecimentos que são produzidos em nossa área para auxiliar na desconstrução do preconceito instituído perante esse grupo de pessoas. Ainda que não esteja previsto no currículo básico trabalhar a evolução humana dentro de uma perspectiva de combate ao racismo estrutural, esse assunto enquanto conteúdo educacional é uma ótima oportunidade de transversalizar o tema racismo, pois desperta grande interesse e curiosidade nos estudantes. A atividade aqui apresentada requer alguns conhecimentos prévios de genética básica, expressão gênica, evolução e seleção natural. Pode ser desenvolvida de forma interdisciplinar com as disciplinas da área de ciências humanas (história, geografia, filosofia e sociologia), não requer materiais de difícil acesso por parte do aluno e do professor e a construção do conhecimento é toda protagonizada de forma dialógica com os estudantes (FREIRE, 2007). Aprofundar uma pesquisa em sala de aula que discuta o conceito de raça e as evidências biológicas que fundamentam essas discussões é importante para o desenvolvimento de um cidadão crítico, que compreende todas as injustiças sociais as quais os negros foram e continuam sendo submetidos ao longo de toda a sua história no nosso país e também em outros países.

Da mesma forma, a metodologia de ensino por investigação é uma ótima estratégia para que conhecimentos transversais como o racismo e as relações étnico raciais sejam compreendidos a partir do viés dos conteúdos e conhecimentos produzidos pelas ciências biológicas.

\section{AGRADECIMENTOS}

O presente trabalho foi realizado com o apoio da Coordenação de Aperfeiçoamento de Pessoal de Nível Superior - Brasil (CAPES) - Código de financiamento 001.

Health and Biosciences, v.1, n.3, Dez. 2020

Disponível em: https://periodicos.ufes.br/healthandbiosciences 


\section{REFERÊNCIAS BIBLIOGRÁFICAS}

1. CASTRO MAT. A evolução humana na disciplina de biologia e as relações étnico-raciais: aprendizagens a partir de uma intervenção educativa. Dissertação (Mestrado em Educação), Centro de Educação e Ciências Humanas, Universidade Federal de São Carlos, São Carlos, 2018, $128 f$.

2. FREIRE P. Pedagogia do oprimido, 46.ed., Rio de Janeiro: Paz e Terra, 2007, 213p.

3. GRAVINA MM. Por que discutir racismo em aulas de biologia? Instituto Ciência Hoje. Disponível em http://cienciahoje.org.br/artigo/por-que-discutir-racismo-em-aulas-debiologia/. Acesso em 15 de outubro de 2019.

4. KRASILCHIK M. Prática de Ensino de Biologia, São Paulo: Editora da Universidade de São Paulo, 2008, 200p.

5. PEDASTE M, MÄEOTS M, SIIMAN LA, DE JONG T, VAN RIESEN SAN, KAMP ET, MANOLI CC. Phases of inquiry-based learning: Definitions and the inquiry cycle. Educ Res Rev 14: 47-61, 2015.

6. PENA S, BIRCHAL TS. A inexistência biológica versus a existência social de raças humanas: pode a ciência instruir o etos social? Rev USP 68: 10-21, 2005-2006.

7. SANTOS FR. A grande árvore genealógica humana. Rev UFMG 21(1 e 2): 88-113, 2014.

8. SASSERON LH, CARVALHO AMP de. Alfabetização científica: uma revisão bibliográfica. Invest Ens Ciênc 6(1): 59-77, 2011.

9. SCARPA DL, SILVA MB. A biologia e o ensino de ciências por investigação: dificuldades e possibilidades. In: Carvalho AMP editor. Ensino de ciências por Investigação: condições para implementação em sala de aula, 1.ed., São Paulo: Cengage Learning, 2013, 164p.

10. SCHWARCZ LM. Sobre o autoritarismo brasileiro, 1.ed., São Paulo: Companhia das Letras, 2019, 288p. 